\title{
Leveraging human nutrition through livestock interventions: perceptions, knowledge, barriers and opportunities in the Sahel
}

\author{
Paula Dominguez-Salas ${ }^{1,2,3}$ • Domitille Kauffmann ${ }^{4} \cdot$ Christophe Breyne $^{5} \cdot$ Pablo Alarcon $^{6,3}$
}

Received: 8 March 2018 / Accepted: 1 July 2019 / Published online: 19 August 2019

(C) FAO 2019

\begin{abstract}
The potential of livestock and animal-source foods (ASF) to improve nutrition of vulnerable households in the Sahel countries is large, but currently underutilised, despite the dependence of human nutrition on livestock in some areas. This study assesses the perceptions of the linkages between livestock and human nutrition interventions by West African implementers; the challenges faced; and the lessons learnt to significantly leverage nutrition in livestock interventions. Here, we report a qualitative study combining: 1) a formative research with semi-structured interviews of key informants $[n=36]$, and thematic analysis; and 2) a participatory work conducted during a regional workshop. Results were grouped to provide insights into several aspects: a) dietary, storage and preservation practices of ASF, b) livestock-human nutrition impact pathways, c) interventions with potential to improve nutrition, d) monitoring and evaluation, e) coordination issues, and f) knowledge gaps. Thirteen pathways were identified through which livestock impacts human nutrition, each presenting different trade-offs. About $79 \%$ of the participants of the workshop and working with livestock reported to never having monitored outcomes of attempts to improve human nutrition. Lessons learnt highlighted the importance of local ASF taboos and beneficiary targeting and identified promising interventions. The principal challenges identified were related to capacity-building, programming, or to funding issues. There was agreement among stakeholders on the importance of livestock and ASF to improve human nutrition, and on the prominent disconnect whereby livestock interventions often neglect human nutritional goals, due to the complexity of impact pathways and the multiple roles of livestock in livelihoods. Stronger collaboration among researchers and implementers could contribute to expanding the body of evidence. This compilation of insights could promote dialogue and guide further progress.
\end{abstract}

Keywords Nutrition $\cdot$ Livestock $\cdot$ West-Africa $\cdot$ Impact pathways $\cdot$ Interventions

\section{Introduction}

Malnutrition represents the single most important threat for children worldwide and brings about substantial

Electronic supplementary material The online version of this article (https://doi.org/10.1007/s12571-019-00957-4) contains supplementary material, which is available to authorized users.

Paula Dominguez-Salas

paula.dominguez-salas@1shtm.ac.uk

1 London School of Hygiene and Tropical Medicine (LSHTM), Keppel Street, London WC1E 7HT, UK

2 International Livestock Research Institute (ILRI), P.O. Box 30709, Nairobi 00100, Kenya

3 Leverhulme Centre for Integrated Research in Agriculture and Health (LCIRAH), 36 Gordon Square, London WC1H 0PD, UK impacts both on humans (health and cognitive) and economic potential (Black et al. 2013). In recent years, the reduction of malnutrition has become a top policy priority in low- and middle-income countries through
Nutrition and Food Systems Division, Economic and Social Department (ES), Food and Agriculture Organisation (FAO, Rome), Viale delle Terme di Caracalla, 00153 Rome, Italy

5 Nutrition and Resilience Division at Sub-Regional Emergency Operation and Rehabilitation Office for West Africa and Sahel (REOWA), FAO, 15 rue Calmette x rue Amadou Assane Ndoye, 3300 Dakar, BP, Senegal

6 Royal Veterinary College (RVC), Hawkshead Lane, Hatfield, Hertfordshire AL9 7TA, UK 
initiatives such as the 'Scaling Up Nutrition' (SUN) movement (SUN 2011). At the same time, an increasing commitment to promote sustainable agricultural development and ensure food security worldwide is reflected in the 'Post-2015 development agenda' Sustainable Development Goals (SDGs) (UN 2015). The Lancet Series on Maternal and child nutrition in 2013 (Ruel et al. 2013) emphasized the need to address all forms of malnutrition, by combining nutrition-specific interventions (i.e. addressing immediate determinants of malnutrition) with nutrition-sensitive interventions (i.e. addressing underlying determinants) in different areas, including agriculture (Haddad 2000). Also, the Second International Conference on Nutrition (ICN2) led to a commitment from world leaders to establish national policies aimed at eradicating malnutrition and transforming food systems to make nutritious diets available to all (FAO/WHO 2014). On April 2016, the United Nations General Assembly proclaimed 20162025 the Decade of Action on Nutrition calling for eradication of hunger and malnutrition in all their forms and in all age groups (UN 2016).

Worldwide, malnutrition accounts for $45 \%$ of child mortality (Black et al. 2013). Africa is the continent that has made the least progress in reducing the prevalence of malnutrition, and after a decline, malnutrition is on the rise again (UN 2018). In West Africa, food insecurity crises have been recurrent, and malnutrition rates remain well above international emergency thresholds even in years with acceptable harvests (OCHA 2016). Acute malnutrition (wasting) ranged from $6 \%$ in Senegal to $19 \%$ in Niger and stunting rates have varied from $19 \%$ in Senegal to $43 \%$ in Niger (UNICEF 2016) (see Supplementary Table 1). Low birth weight (with prevalence up to $35 \%$ in Mauritania) is also alarming (UNICEF 2016) 1) (see Supplementary Table 1). In this region, the slow progress towards the SDGs is of major concern (IFPRI 2016), especially with demographic growth which is faster than the improvements in nutrition (African Union 2017).

At the same time, in the Sahel's arid and semi-arid areas, the potential to produce food of plant origin is limited and livestock production has traditionally been a key resource (e.g. nearly $40 \%$ of the Chadian population is engaged in the livestock sector, making up to $20 \%$ of GDP (Wiafe-Amoako 2016)), contributing to poverty alleviation and dietary diversification. Animal-source foods (ASF) are food groups dense in macro- and micro-nutrients (see Supplementary materials Table 2). In these countries, where widespread micronutrient deficiencies exist (e.g. iron-deficiency anaemia or vitamin A deficiency), poor households' diets are frequently limited in variety and are low in micronutrients (Grace et al.
2018). Appropriate complementary feeding practices, rich in nutrient-dense foods, have shown a protective effect against stunting (Bhutta et al. 2013). Poor children's diets may be particularly low in ASF, which are often considered luxury foods. In Kenyan school children, meat supplementation improved cognitive and behavioural outcomes, as well as physical activity (Grillenberger et al. 2007). Similarly milk supplementation improved child growth (Grillenberger et al. 2007; Sadler et al. 2009). Challenges to ASF consumption in poor households include: lack of availability and economic access, poor food safety and production practices, and limited understanding of the value of ASF in maternal and child nutrition. Therefore, the contribution of ASF to human health, particularly during the first 1000 days of life (from conception up to two years), have to be considered in food and nutrition policies and programs. This is particularly relevant in regions where substantial livestock production and malnutrition coexist, and ASF are barely consumed. In addition, livestock can contribute to increased nutrient-dense food consumption through other pathways. Improving the efficiency of livestock food systems thus appears as a key opportunity for these countries to reduce malnutrition (Randolph et al. 2007).

Nutrition-sensitive, multisectoral programs are receiving increasing attention. Nonetheless, our knowledge about the linkages between agriculture and nutrition are still limited (Picchioni et al. 2017), particularly in respect to what is cost-effective and works for scaling up interventions. Agriculture interventions are not always specifically oriented towards achieving positive nutritional outcomes and, when not correctly planned, they can even have a negative impact on nutrition (Randolph et al. 2007; Swanepoel et al. 2010; Webb 2013). Evidence for the impact of applying a nutritional lens to agriculture interventions is generally sparse. Gaps in evidence are even more important in the livestock subsector, where different systematic literature reviews have identified that livestock interventions have not yet effectively considered nutritional outcomes and that the number of studies assessing impact of suitable quality is even scarcer (Leroy and Frongillo 2007; Masset et al. 2012; Grace et al. 2018). Given the increasingly competing priorities for funding, optimisation of resources and evidence-based decision-making should be encouraged. Livestock development work, when appropriately designed, can also contribute to gathering this body of evidence and making a positive change.

Within this context, the objective of this study was to assess the current state of knowledge and perceptions in the region and to identify barriers and opportunities of livestock development to achieve nutrition impact. For 
this purpose, this research focuses on three main aspects: 1) the linkages between livestock and human nutrition for poor livelihoods in the Sahel; 2) the 'lessons learnt' from the region and knowledge gaps; and 3) the challenges and constraints to integration of livestock development and human nutrition.

\section{Methods}

In preparation for the qualitative work, an extensive literature review identified the most relevant livestockhuman nutrition interventions and stakeholders. This also included an assessment of the different frameworks used to map agriculture (and/or livestock) and human nutrition linkages. Subsequently, qualitative research with key informant interviews (KIIs), and a regional participatory workshop (RPW), was conducted between August and December 2014. For simplicity, the term 'nutrition' will refer to human nutrition unless otherwise specified. The research focused on vulnerable populations in the West African Sahel, particularly on populations whose livelihoods are based on livestock, and with high prevalence of malnutrition.

\subsection{Key informant interviews (KIIs)}

Semi-structured interviews were conducted to gather perceptions and experiences from key experts working in livestock and/or nutrition fields throughout the region. These interviews aimed to: 1) investigate the importance placed on the linkages between livestock and nutrition in programme planning; 2) assess the types of livestock-nutrition interventions implemented and the lessons learnt; and 3) identify the key facilitating factors and barriers, as well as the existing gaps in knowledge and coordination aspects.

The study included 36 key informants from 27 national and international organisations or institutions working in West Africa in technical positions related to livestock and/or nutrition. The selection of the interview participants was purposive, based on relevant experience, and representation of the different categories of stakeholders: i) donors; ii) implementing agencies (e.g. humanitarian NGOs); iii) government institutions; iv) international organisations (i.e. United Nations agencies) v) private sector (producer associations and cooperatives); and vi) research institutions/academia. Participants were recruited, based on existing information networks and snowball techniques. They were selected on the basis of operating in one or more of the six Western Sahel countries (Burkina Faso, Chad, Mali, Mauritania, Niger and Senegal), and having hands-on experience. Representation from all countries was ensured. Some key informants not specific to these countries but with specific knowledge on relevant topics or tools (such as Livestock Emergency Guidelines (LEGS)) were also interviewed. Interviews were conducted face to face, via telephone, or via Skype. Oral consent was obtained from each participant.

Interviews were conducted using a semi-structured questionnaire. Leading questions were avoided; however, prompts were included to help in the narrative of the respondents. The order of the questions during the interview was not linear to facilitate interview flow. Written notes were taken for all the interviews. Some interviews were audio-recorded for quality purposes, after permission was granted, and detailed summaries produced. Data were coded into templates, grouping the information obtained from the interviewee into different topics. A thematic qualitative analysis was subsequently performed by the authors, using an Excel template to identify the emerging themes.

\subsection{Regional participatory workshop (RPW)}

The objective of the regional workshop on 'Livestock, Livelihoods and Nutrition in Emergency and Building Resilience' was to create the conditions for experience sharing and participatory discussion between nutritionists and livestock experts, on how to integrate livestock and nutrition in programme planning, and the synergies and challenges for collaboration between both disciplines. A conceptual note was conveyed through multiple channels (e.g. Nutrition and Food Security Clusters, Food Security groups, international theme mailing-lists, etc.) to disseminate the information about the workshop. Application to the workshop was made online via 'SurveyMonkey' (SurveyMonkey Europe, Dublin, Ireland). Applicants needed to indicate their expertise in the sector(s), motivation to participate and possible contribution to the discussions (e.g. relevant case studies to be presented). In response to the call, 130 forms were received from which 60 participants were selected according to: balance in the distribution of representatives (maximum one representative by organisation and country), balance between organisations and expertise sectors, and the organisational needs (e.g. contribution to the workshop with relevant specific experiences) (see Supplementary Table 3). The same categories of stakeholders as for the KII were included. The RPW was held in Dakar between 5 and 7 November 2014, and participants from the six target countries were fully funded to attend. A steering committee (FAO, RVC/ ILRI) was created to select the participants, and prepare and facilitate the workshop. 
The workshop agenda, based on the KIIs, alternated theoretical training sessions, to ensure a baseline of knowledge among participants from all disciplines, with group work, to share opinions and experiences. The three days were organised in six sessions: 1) Baseline concepts and context; 2) Situation analysis; 3) Interventions: case study presentations; 4) Interventions: response analysis and project design; 5) Monitoring and Evaluation; and 6) Coordination and implementation challenges.

Different group exercises, where participants discussed specific topics in small groups ( $\sim 10$ people) before sharing and discussion in a plenary session, were facilitated by one researcher who ensured participation, and recording participants' responses. These activities included:

1. Identification of ASF taboos, dietary practices and preservation methods.

2. Development of impact pathways from livestock to human nutrition.

3. Effect of crises situations on impact pathways.

4. Design of crises responses to mitigate nutrition consequences.

5. Identification of lessons learnt.

6. Identification of challenges in coordination.

These activities had been pre-tested with other researchers at RVC in London. In addition to these exercises, short feedback surveys were conducted during the workshop, and summarised in Excel. Working documents from the workshop are available at (http://www. fao.org/in-action/food-security-capacity-building/events/ detail-events/en/c/248628/).

\section{Results and discussion}

The results presented hereafter are a compilation of emerging themes and ideas collected from the KIIs and the RPW group discussions combined. The majority of the KII participants welcomed the RPW initiative as 'much needed' due to the widespread disconnection between livestock and nutrition, whose linkages require strengthening. Their suggestions for the RPW, which contributed to the design of the RPW activities, are summarised in the Supplementary materials Box 1. This disconnect was confirmed during the RPW, where $83 \%$ of participants responded that nutrition is not perceived as a priority by livestock experts, and $73 \%$ responded that livestock and ASF were not perceived as priorities by nutrition experts. Only $30 \%$ of the participants considered themselves to have a good knowledge about the linkages between livestock and human nutrition.

\subsection{Situation assessment - diet, preservation and storage practices related to ASF}

Participants from both KIIS and RPW agreed that to assess the relevance of ASF in a population it is first necessary to understand: i) what the key nutritional deficiencies are, ii) the role of ASF in their diets and iii) how dietary diversification with ASF can contribute to closing the existing nutrient gaps. Participants widely acknowledged that cultural beliefs and practices, including taboos, can be important barriers to adequate nutrition and ASF consumption (see Table 1). Some ASF were seen to be particularly restricted to those in need (i.e. women and young children), due to gender norms affecting intra-household allocation of ASF. It was believed to be usual in many households that men eat first, consuming the foods of higher quality, followed by women and small children. It was mentioned that the man often distributes the meat pieces among the members of the family at his discretion, and their focus may not always be given to children and pregnant women. In addition, many of the taboos reported focused on women and children. Whilst the origin of some of these taboos was thought to possibly be accidental (e.g. unlucky coincidences of women eating red meat and bleeding profusely during delivery), it was believed that most of them were calculated responses to avoid possible problems (e.g. avoid too largefor-gestational-age babies and thus, prevent labour problems) or to protect the economic or social structure of the household (e.g. prevent children from taking eggs and ensuring that they are used for reproduction of poultry and/or selling the offspring and products to fulfil small household economic needs) and may now be deeply rooted in the dietary practices.

Several participants indicated that some notion of the importance of ASF exists among households in the region (e.g. the view that 'milk is the most complete meal', as 'it is the first food for babies and the best food for elderly'; it is also considered to be a healthy product because of 'being the first and last meal to enter the body'). However, there is a generalised lack of knowledge about the nutritional content, properties, safety and adequate use of ASF. One participant explained that this lack of awareness might contribute to households shifting the need for quality and balanced diet to upper layers of the Maslow's 'Hierarchy of needs' pyramid ${ }^{1}$ (the less important needs), with basic needs being the elimination of appetite ('getting the stomach full') (Maslow 1943). These results indicate that indeed, food practices are extremely complex and even if sometimes dangerous, they form an integral part of cultural behaviour in traditional societies which are difficult to change (Meyer-Rochow 2009), particularly if they

\footnotetext{
${ }^{1}$ The basic four layers of Maslow's pyramid contain "deficiency needs" (esteem, friendship and love, security, and physical needs. When the "deficiency needs" are not met, the individual will feel anxious and tense. Maslow's theory suggests that these basic needs must be met before individuals will strongly desire or focus on higher level needs.
} 


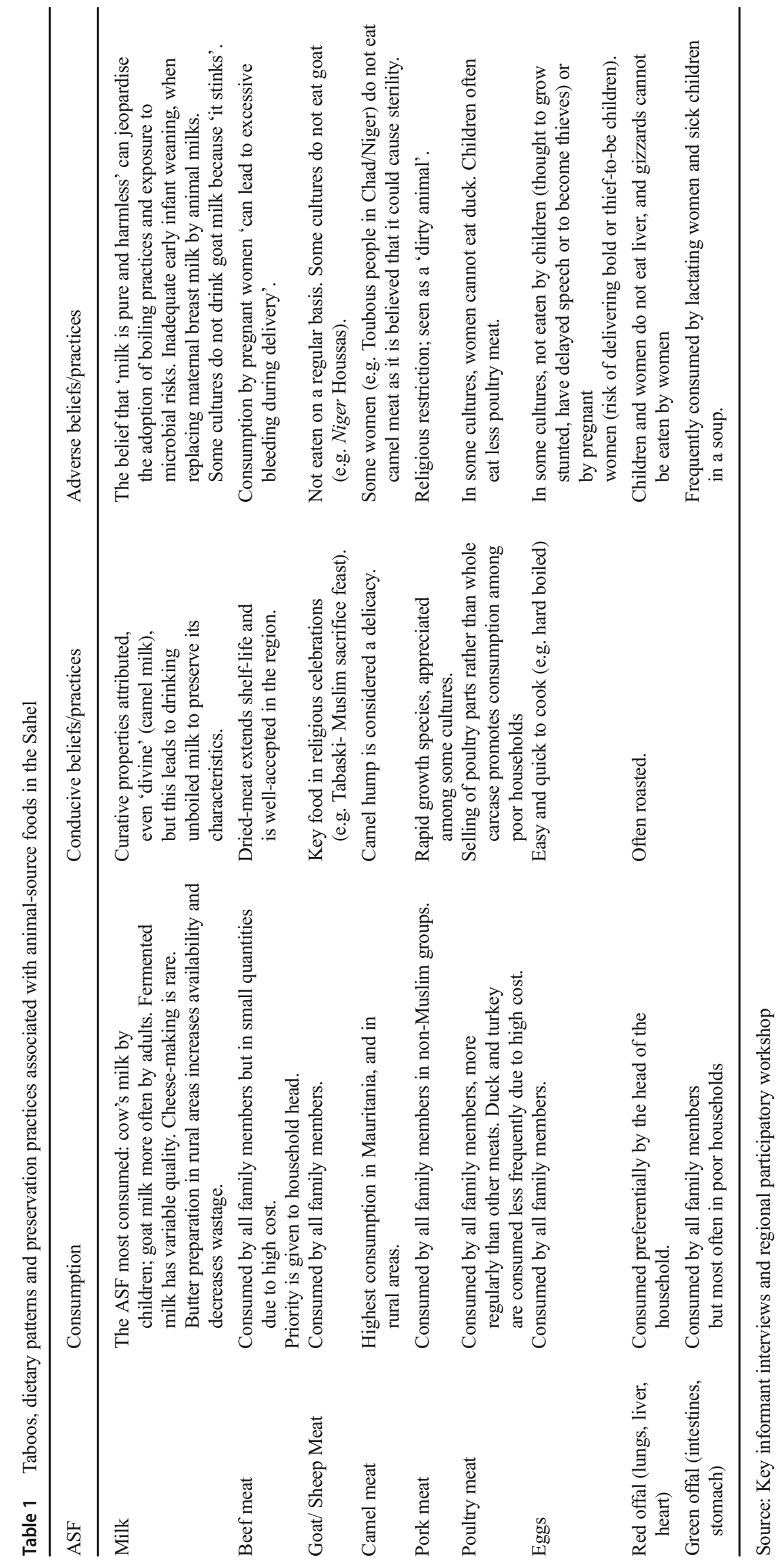


are not correctly assessed. Therefore, food and nutrition security programs could benefit hugely from applying a socioanthropological lens in their design and implementation, in a context-specific manner. Interventions aiming at producing ASF for nutrition security should include a 'Social and Behaviour Change Communication' (SBCC) strategy to promote their uptake at the dietary level (or alternatively to trade them for other nutritious food groups) (Miller et al. 2014).

Preservation and storage methods of ASF in the Sahel were seen as a major concern, especially in areas without access to fridges, resulting in limited availability of these products to the household all year round. Moreover, bad practices (poor preservation or inappropriate handling of ASF) were indicated to lead to food safety, health and nutritional problems. Understanding specific practices, enhancing and hindering drivers (including gender and taboos for ASF consumption) were considered essential to the successful design and implementation of a nutrition-sensitive livestock intervention (Meyer-Rochow 2009; Miller et al. 2014). Also, food safety in relation to ASF and nutrition was identified as an area with important evidence gaps. Rapid risk assessment methodologies are being developed and can be considered (Deka et al. 2012; Bonfoh et al. 2014; Haesler et al. 2014). Particularly, risk assessment of ASF may indicate that hazards are destroyed during household preparation, but this might not always be the case. For example, some pastoralist populations do not want to alter the 'mystic' properties of milk through boiling (Haesler et al. 2014). Heat treatment of ASF might be short or completely avoided if there are insufficient resources to purchase fuel. In addition, pasteurisation changes the taste of milk, and fresh milk is then often preferred. Developing, perfecting and introducing appropriate (traditional) preservation technologies, that consider household cultural norms and resource limitation, could contribute in a 3 -fold way to overcoming concerns associated with ASF, namely shortages due to seasonality (e.g. scarcity of milk during the dry season), presence of food safety hazards and short product shelf-life. Furthermore, inadequate preservation techniques, involving excessive boiling, sun exposure, and others, may harm ASF and result in loss of nutrients such as vitamin C or riboflavin (FAO 1992, FAO 2013a).

\subsection{Impact pathways}

Figure 1 compiles the impact pathways related to livestock that can result in improved or impaired nutrition, as identified by participants.

The pathways in Fig. 1 relate to the multiple functions of livestock for households or society, which may interact and present numerous feedback loops. They were described by participants as:
'Own-consumption': Consumption of ASF produced in the household is the most direct pathway leading to improved nutrition and was often believed to be the main reason for vulnerable households with subsistence agriculture economies keeping livestock. The evidence for the role of ASF in improving micronutrient status in breastmilk, infants, children or women of reproductive age is limited (Grace et al. 2018), but the micronutrient content in ASF and the high bioavailability of their chemical presentation makes it reasonable to expect potential impacts.

Despite this, participants perceived a tendency to first consider livestock as an income generating activity, rather than as a food source. The suitability of the different species for using own-consumption instead of the 'Income' pathway (described below) was reported to require careful consideration (e.g. milk and eggs allow for 'daily family portions' while bovines tend to be sold as live animals and are more difficult to manage or evaluate for own-consumption). Furthermore, it was stated that production needs to be sufficient to allow for own-consumption after selling, and that increases in productivity and market opportunities need to ensure that this pathway is maintained without income interference' (i.e. that increased access to market and sales opportunities do not reduce the part of ASF kept for household own-consumption). 'Income interference' was believed often to result in consumption of less nutritious foods and increased risk of malnutrition (e.g. farmers may know that their milk is highly nutritious, yet they may not produce enough volume to both sell and consume). In some settings it was reported that households owning dairy cows may prefer to sell their milk and use the cash obtained to buy other less nutritious foods (e.g. basic components of the diets such as rice, groundnuts, and oil) that guarantee three meals a day and 'full stomachs' throughout the day, particularly during periods when maintaining the number of daily meals is a challenge. It was also mentioned that local milk market prices might be higher than imported milk (powdered milk or soya) prices, becoming an incentive to sell milk rather than to consume it. This pathway can also be influenced by factors such as socioeconomic status, cultural taboos, opportunities or capacity for ASF storage and preservation and at individual level, by gender and intra-household food allocation.

'Income': This pathway refers to the availability of money in the household as a result of livestock-related activities. It was identified as contributing positively to household nutrition, directly though purchase of nutritious foods (either ASF or non-ASF) and access to health care, or indirectly through better education or purchase of non-food related goods (e.g. 


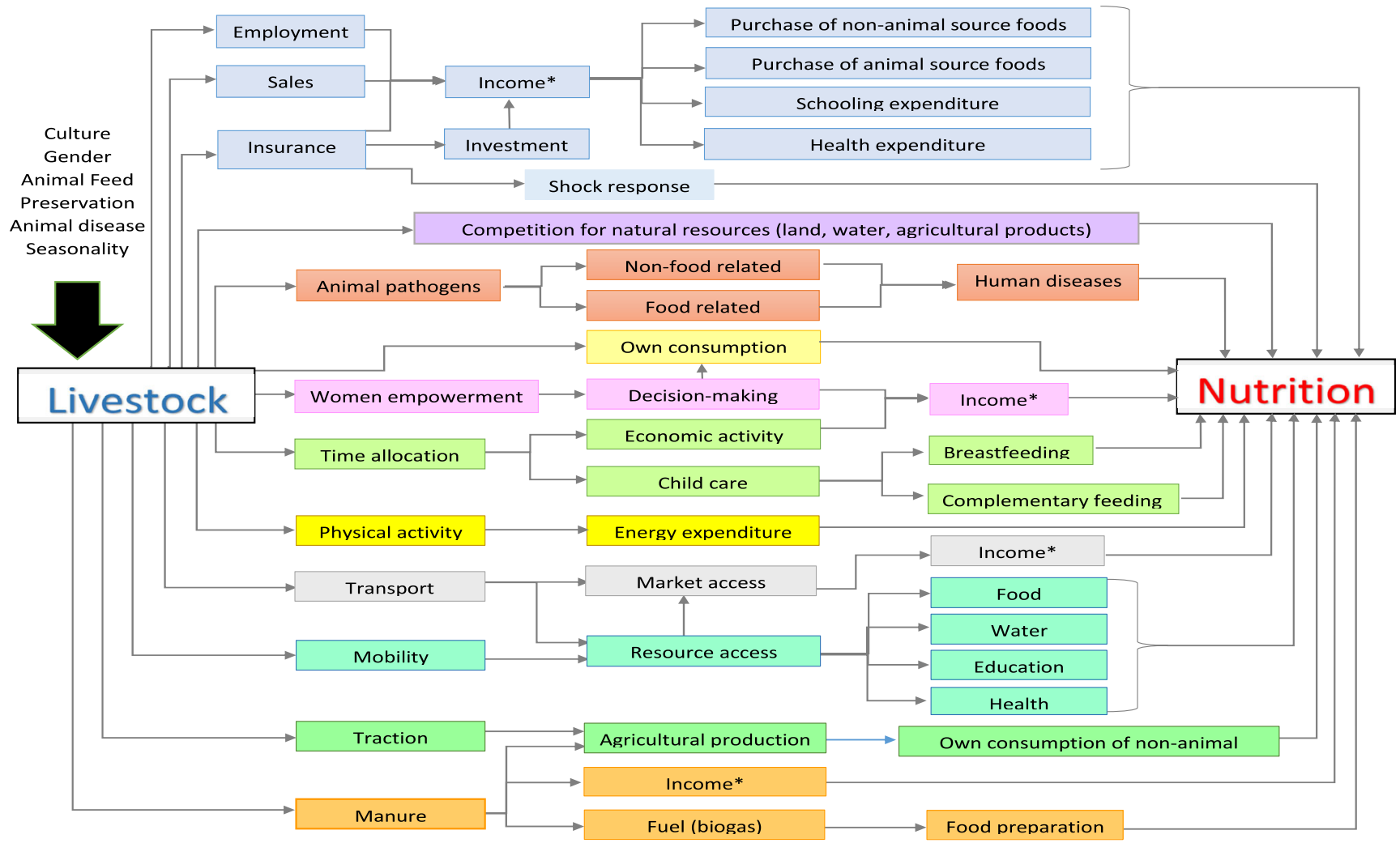

Fig. 1 Diagram of impact pathways through which livestock can affect nutrition. Pathways identified during the workshop 'Livestock, livelihoods and human nutrition', Senegal, November 2014. Note: This diagram simplifies the pathways for practical use; it must be noted that they are often used simultaneously, and present interactions and feedback loops fuel, soap, kitchen tools, investment in better housing and water and sanitation standards). However, some of the uses of the income generated might not result at all in improved nutrition outcomes and on occasions, can even have a negative effect (e.g. purchase of undesirable processed foods such as soft drinks). Several sub-pathways were identified:

- 'Sale': Income resulting from the sale of livestock commodities (live animals or their products) was the most direct sub-pathway. Income management (i.e. decision-making and expenditure patterns) was seen as one of the most important factors impacting household diet (quantity and quality), human disease prevention and treatment.

- 'Employment': Livestock production or associated value chains (e.g. shepherds, workers, butchers, retailers, etc.) were seen to offer numerous employment opportunities, playing essential roles as sources of income for other households in the community.

- 'Insurance': In many Sahelian communities, livestock (particularly cattle), were reported to have a role in 'banking' and capital accumulation as an alternative to institutions (banks), providing a better investment return through reproduction and other services. Livestock is a means for quick cash access, from the sale of animals in the event of crises; as a result, livestock ownership is considered a mark of prestige. Thus, it can have a direct role in nutrition, when money is released to confront household food insecurity situations or health problems. However, it was also said that this was not always the case, as many communities were reluctant to sell animals even when there were vital family needs. Indeed, the sale of animals and particularly good animals by pastoralists was often considered an indicator of vulnerability (e.g. selling reproductive animals is seen as a last resort, as it depletes productive assets with irreversible consequences in the capacity of the household to recover production). Similarly, livestock ownership was said to facilitate access to re-investment in the livestock business, or in other economic activities that may help the household get out of poverty and ultimately improve nutrition. However, among pastoralists this is often not the case, as they are sometimes reluctant to sell animals and invest in business innovation opportunities.

Other pathways identified had the potential to end up as 'Income' or 'Own-consumption' pathways, serving specific purposes: 
- 'Transport': Certain animals (horses, donkeys, oxen and cows) were reported to be a means of transport, facilitating market access for selling or purchasing agricultural food products, thus contributing to income generation and increasing diet diversity. Transport was also said to increase access to clean water, health care or education, which ultimately improve nutrition through preventing disease and increasing householders' knowledge of nutrition. Using animals to provide transport services was also considered an incomegenerating activity.

- 'Traction for agricultural work': In mixed systems, animals were mentioned as crucial sources of power in the fields. Uses of this power includes preparing the soil, sowing and harvesting, thus contributing to better agriculture yields or to more time-efficient agricultural activity and ultimately to improving food access ('own-consumption') and income. Renting of animals for draught power for agricultural work was also linked to the 'Income' pathway.

- 'Manure': Nutrient cycling services were linked to increased crop production for food, increasing household food availability (non-ASF 'Own-consumption' pathway), or sale ('Income' pathway); manure contracts between pastoralists and farmers seem to be scarce despite its win-win aspect. It was also reported that some households use or sell manure as fuel to cook food, which can save time and money in obtaining other types of fuels or preserve low wood resources. The production of biogas from manure was also identified as an incomegenerating activity.

Closing the gender gap in agriculture was believed to be paramount in increasing productivity, but also in affecting maternal and child nutrition in three ways:

- 'Women's autonomy and empowerment': Some species, such as dairy goats or cows and poultry, were thought to be more frequently kept next to households and to be reared by women, combined with other activities such as child care. These species were perceived to be more likely to provide income for women, who were reported to be more likely to use this income to improve child health and nutrition. Increasing women's decision-making over the management of animals and income expenditure was believed to be key to fostering own-consumption and quality of diets, as well as to generate more rational and fairer intra-household distribution. Measures to increase women's resources were said to have long-term effects on nutrition. Participants identified challenges faced by women such as illiteracy, early marriage, longer workdays, lower social status, less technology access, higher responsibility for family members, which have downstream effects in decisionmaking and nutrition.

- 'Time allocation': Livestock activities (feeding animals, milking, cleaning, etc.) were described as highly time-consuming. These tasks are performed mostly by women and may interfere with other activities and practices which are associated with good nutrition (e.g. breastfeeding, child care, care of other members of the family such as the elderly or cooking and the preparation of balanced meals).

- 'Physical activity': Some livestock activities were also reported to require substantial physical effort (e.g. transhumance), which may increase expenditure of energy of all the members of the household and particularly women and children, leading to increased nutrient requirements, and to malnutrition when these are not met.

Finally, pathways related to other health, geographic or productive aspects were identified:

- 'Animal disease': Several participants mentioned the role of zoonoses (pathogens transmitted from animals to humans) in health and poor nutritional status due to nutrient losses through diarrhoea, loss of appetite, etc. Transmission of pathogens from animals to humans was said to occur through ASF contamination (foodborne), direct contact with animals or their excretion products (faeces, urine, saliva, etc.) or from environmental contamination including water resources. Furthermore, diseases in adult livestock were linked to loss of production capacity and increased veterinary expenditure, affecting the 'Own-consumption' and 'Income' pathways. Therefore, activities for disease control and appropriate management of livestock waste were identified as important interventions in order to avoid the risk of malnutrition.

- 'Mobility': Nomadic pastoralists were described as travelling long distances looking for good pastures and water for their animals, particularly during droughts. Such travel often involves relocation to isolated areas, with little access to food markets, health services and vaccination, school, nutrition programmes, etc. This was said to particularly affect women and children, when the whole family travels. To avoid this, some participants explained that pastoralists frequently use the 'base residence-satellite camp' model, where only older boys and men travel, while the rest of the households (women, younger children and the elderly) remain sedentary at the base camps. However, this was also believed to have drawbacks, 
as members remaining behind without animals do not always benefit from their products (e.g. milk). In addition, they also reported that livestock extension workers generally do not have access to those herds, which are often in a fragile state, in remote locations.

- 'Competition for natural resources': effects of livestock in crop agriculture production can also be negative. For example, land allocated to livestock or to production of fodder for livestock can lead to a reduction in available cropland for production of human food. Access to land is frequently the main constraint, especially for poor livestock keepers, leading to lack of access to grazing land and water. Moreover, the increased risk of drought challenges the availability of quality pastures and fresh water, resulting in land conflicts between farmers and herders as animals occupy agricultural areas.

Participants identified multiple purposes for households to keep livestock (e.g. high quality food products, income, draught power, as financial instruments, enhancement of social status, religious purposes and cultural and ecosystem services, etc.) that have been described in the literature (Swanepoel et al. 2010). This multiplicity of purposes can sometimes explain the lack of positive impact of livestock interventions on nutrition. Increasing nutrition knowledge and education can be conducive to positive impacts. On the contrary, crises such as armed conflict, droughts or flooding, were said to lead to forced migration with the animals or to a loss of animals (due to theft or animal death), and consequently to a negative impact on the nutrition of households heavily dependent on livestock livelihoods. In such situations, some livestock keepers prioritise livestock well-being over the nutritional and well-being needs of their households, when challenges such as droughts, conflicts or volatility of market prices occur. As a consequence, patterns of human population mobility can be heavily influenced by animal needs (FAO 2015 b). Index-based livestock insurance has been developed and implemented to protect rural smallholder keepers of livestock from drought related asset losses, thus reducing climate-related risk (McPeak et al. 2010; Bageant and Barrett 2017; Jensen and Barrett 2017). These and other crises such as economic difficulties and animal disease outbreaks, were said to result in market disruption and lack of functionality for either buying or selling food products, thus affecting many of the pathways discussed. Therefore, it is important to make a distinction between humanitarian and development projects, but the basic pathways may consider both. In addition, these pathways were perceived to be affected by the efficiency of livestock production in a given year and by the end quality of products, which depend on: i) animal feeding (affecting milk quantity and quality, carcase quality, and animal morbidity and mortality); ii) cultural breeding practices; iii) animal disease control; iv) ASF preservation techniques; v) seasonality; vi) climate change, and other factors.

UNICEF's malnutrition causal framework is a powerful tool for nutritionists, but it is not so intuitive for other professionals and makes it difficult to zoom in on specific sectors (Black et al. 2008). The impact pathways leading to good or poor nutrition from agricultural production were first described by Haddad in 2000 (Haddad 2000). Randolph et al. described the specific livestock pathways in 2007 in a very useful framework (Randolph et al. 2007), and Dury et al. identified the main risks (Dury et al. 2014). However, participants were not familiar with Randolph's livestock-nutrition framework or found it overwhelming. The complexity of interactions is not well considered or monitored by practitioners in the field. Impact pathways disentangled here were used to understand the implications and anticipate and track the chain of consequences, roadblocks and side-effects arising from specific crises or context changes (such as droughts, economic crises or conflicts). Building on those, the potential solutions and interactions in the system can be identified. Some of the pathways are less intuitive, such as the gender pathway (e.g. the effect of time allocation and physical activity on nutrition) and are more likely to be overlooked. However, the importance of these pathways has been thoroughly researched by other disciplines (FAO 2011; Johnston et al. 2015; Njuki et al. 2015). Generally, several pathways coexist, but the relative importance of each pathway can vary substantially by setting and depend on the local context. It is also important to note they do not have the same absolute weight in nutrition. The unpacking of pathways seemed to help participants visualise clearly the positive and negative nutrition impacts that livestock could generate, and conceptualise the key parameters for programme design, monitoring and evaluation. In some cases, the solution might not need to be producing more, but to ensure that the production is nutrition-sensitive. Household prioritisation and undesirable practices can be shaped and addressed through a nutrition SBCC strategy to promote the right choices, with specific attention to 'income interference' (Swanepoel et al. 2010). Livestock owners should also visualise the nutrition potential to make the most of their business for household nutrition. ASF are normally associated with wealth as higher-income households eat more ASF than poor households (Speedy 2003; Baker et al. 2016). The small amount eaten by the latter often comes from their 
own production (Sandford and Ashley 2008), and some studies done in Africa showed that livestock keepers are more likely to eat ASF than non-livestock keepers (WorldBank 2014; Hetherington et al. 2017), although it is not always necessarily own-produced. An important premise of many livestock projects (i.e. that the income generated will ultimately improve nutrition security) is not supported by empirical studies, as changes in incomes do not immediately lead to a higher consumption of calories or more diverse diets (Leroy and Frongillo 2007; Masset et al. 2012; Grace et al. 2018).

\subsection{Interventions with potential to improve nutrition}

\subsubsection{Types of interventions}

Several participants explained that livestock interventions tend to be more oriented to productivity and small enterprise development than other agricultural interventions that tend to be more focused on subsistence producers and their dietary diversification. Government initiatives were perceived to focus frequently on increasing production of medium and large producers, rather than on vulnerable smallholders. The KIIs suggested that potential of livestock interventions to improve human nutrition exist at three levels: 1) Production; 2) Postproduction (i.e. processing and marketing); and 3) Consumption.

At the production level, the interventions reported were diverse, based mostly on providing inputs such as: animal husbandry (animal management training and disease control), animal transfers (particularly small ruminants, chicken and dairy cows) or cash transfers. These interventions can increase productivity and contribute to nutrition, generally through the 'Own-consumption' or 'Income' pathways. An example given was related to animal husbandry interventions: extending cow lactation periods from 3 to 5-6 months, reducing milk seasonality and increasing milk production and availability throughout the year. It was highlighted that attention needs to be given to the animals kept at base camp during transhumance, to keep them healthy and wellnourished and to ensure good nutrition of vulnerable household members. Other interventions mentioned included implementing more effective early warning systems (for dissemination of information on pastures, market prices, etc.), to avoid household animal and production losses, and for business planning. Poultry transfer was defined by one participant as 'the easiest intervention to improve diets due to its quick results on nutrition. The consumers' preference for local poultry, compared to the exotic broiler, due to taste (exotic broilers are perceived as 'not having taste') was mentioned. Local breeds were said to be frequently considered for interventions, as these are less likely to introduce diseases and are adapted to the environmental conditions; however, their production was reported to be lower. Cash transfer interventions were said to be likely to contribute to production, particularly when conditional on animal feed/inputs.

Post-production interventions identified included: 1) better preservation of ASF (e.g. dry meat, meat meal, cheese, fermented milk) or by-products such as leathers; and 2) the creation of cooperatives for the sale of products and of effective market places, as well as ensuring fair prices, etc. These different types of interventions were reported to target improved nutrition through increased availability of ASF by extending shelf-life of products or reducing product wastage (e.g. milk during rainy periods in rural areas) and through increased income generation. Transformed products can add value to the product and be consumed during the seasons with lower production.

Interventions at consumer level were claimed to have the most direct impact on nutrition. An example given was the redistribution of ASF done by some cooperatives among their members as a fidelity bonus for their regular milk supply. Another example referred to the strategic destocking of animals in crisis situations and their use to supplement meat for households or schools. No effect on nutrition was observed in one such school intervention, possibly due to the small portions given and the short duration. This intervention, however, was said to have contributed to an increase in school attendance. Some participants explained that interventions based on nutrition and hygiene education need to be monitored and evaluated, as knowledge transfer focused only on women may not lead to consumption changes, since they may not be the decision-makers.

\subsubsection{Lessons learnt}

Participants in the KIIs and RPW shared the lessons learnt on the factors to be considered for designing and implementing successfully the interventions presented above. These were grouped into five major themes, including: beneficiary targeting, design, gender considerations, what may work well, and what is less likely to work. Their ideas are compiled in Box 1. Key aspects include assessing the beneficiary acceptance and needs before introducing new technology or animals, as well as giving them 
choice among species. In the case of animal transfers, there is a need to ensure adequate training in animal husbandry and available veterinary follow-up services. Several participants expressed their discomfort with non-specialist agencies implementing animal transfers without providing adequate technical support, as they could increase the risk of household poverty and malnutrition due to extra expenses, work, time, disease spread, and other factors not usually considered.

\section{Box 1 Reported lessons learnt from field interventions to achieve impact in nutrition}

\section{Beneficiary targeting:}

1) Focus on the most-vulnerable households (e.g. young children) is key. Community leaders can help to identify these but can also be biased and influenced by others.

2) Women and children are obvious targets. Elderly people are rarely targeted, despite being nutritionally vulnerable.

3) Value chain actors beyond farmers to ensure sustainability, maintenance of active services and thus livelihoods.

\section{Design:}

1) Stakeholders, including pastoralists, need to be consulted early to ensure ownership and acceptability.

2) Adapting interventions to the local context and livestock activities help to ensure acceptability, because 'people copy badly what is done elsewhere'.

3) Understanding dietary practices and household income expenditure patterns and priorities are key.

4) Thorough assessment on suitability of the area for raising specific species productively.

5) Interventions focused on animal feed, water availability and animal health have succeeded in improving productivity; however, it is unknown whether these have improved nutrition. Nutrition impact needs to be considered from early design stages, including clear nutrition objectives and indicators.

6) Diversification (multiple components) can optimize project efficiency, benefiting from synergies.

7) Technological innovation may be difficult or inefficiently adopted by traditional livestock keepers; simple and replicable technologies might work better, including participatory approaches.

8) A 'business approach' is more likely to be economically efficient and have less 'leaks' than a 'project approach'. 'Social entrepreneurship' can be useful in humanitarian and development interventions, and present fewer regulatory barriers.

9) Awareness raising and higher involvement of government in pastoral issues is needed, since these communities are often far from ongoing interventions in livestock and nutrition.

10) Infrastructure limitations such as roads, transport to market, electricity or water for dairy factories need to be considered in planning and may need upgrading for success.

11).Livestock and nutrition sectors should collaborate from early design stages for technical excellence and successful interdisciplinary approaches.

12) Food safety risks of ASF need consideration, as they impact nutrition and health consequences.

13) Sensitization on human nutrition aspects of livestock extension services and livestock farmer associations are key in reaching out to the smallholders.

\section{Gender considerations:}

1) Women often rear the animals but have less access to extension information than men; impairing interventions' efficacy.

2) Species are usually strongly gender-bound. Those linked to women tend to achieve higher impact in household nutrition. Poultry are more likely to belong to women, but sheep or cattle to men, who frequently use them for purposes other than nutrition.

3) If women's livestock activities become very profitable, they can constitute a source of tension that needs to be addressed, else ownership can easily shift to men.

4) Women's work overload on livestock care must be avoided. Technologies that reduce their workload can impact positively on child feeding and care practices.

5) Community crèches can be a solution for childcare while women are working with livestock.

6) In certain cultures, women cannot conduct abattoir activities, but may participate in food processing.

7) Livestock extension workers tend to interact with men while nutrition workers tend to interact with women, and messages do not always get communicated to family members.

8) Men should not be passive actors in their children's nutrition, and they must be educated and sensitized (as well as grandmothers, who are very influential in the households).

9) 'Schools of husbands' model, where men get actively involved in aspects relative to women could work for nutrition.

10) To overcome taboos on ASF continued sensitization on ASF nutrition value and good preparation practices through different channels is essential.

\section{What can work well:}

1) Short cycle species (poultry, pig) give rapid ASF access.

2) Milk and eggs allow delivery of smaller portions for household consumption than ruminant meat. Fractions of poultry carcasses, instead of a whole carcase, could be more affordable.

3) Supply of animals with different purposes (i.e. as a productive asset vs as a food for children).

\section{What is less likely to work:}

1) Ruminants (for meat) long productive cycles are not suitable for rapid impact interventions.

2) Revenue from the sale of cattle is unlikely to affect nutrition because it often happens a couple of times a year, and is used for specific needs, rather than for daily nutrition.

3) Transfer of a small number of animals (e.g. 3 goats) to households is 
(continued)

4) Linking of livestock activities with nutrition and agricultural production.

5) ASF supplementation in Schools.

6) Strategies to improve seasonality food shortages such as ASF preservation techniques (e.g. dry meat).

7) Cash transfers are a good option to diversify diets while supporting local markets.

8) Livestock interventions should have a sensitization component on human nutrition, using Social behaviour change communication tools.

9) Novel product approaches, particularly for young children (e.g. ground meat for weaning).

10) Interventions towards standards and meat grading would allow lower quality, yet nutritious cuts, to be commercialised at cheaper prices.

11) Better use of media technology for sensitisation

12) Water and sanitation must be considered as factors for environmental disease transmission. not a long-term solution, impairing business survival: 'some studies suggest that 12 Livestock Tropical units are advised for viability of the intervention'; however, donors have difficulty accepting such transfers.

4) Provision of livestock without ensuring animal feeding, veterinary services, etc. may be a burden for poor households.

5) Market prices can get distorted during crises, and poor households may sell both the animals and the animal feed at low prices to speculators, who later sell these back at higher prices.

6) Interventions to increase market availability may find that highly vulnerable households still cannot afford ASF.

7) Interventions not considering the budget management of poor households when milk is the largest income source.

8) Sensitisation on ASF consumption will not work below a minimal household income level, because ASF are sold in exchange for food groups.

9) Malnutrition generally cannot be solved through single sectors but through comprehensive approaches.
Pastoralists in transhumance were identified as important targets for nutritional education interventions, as by migrating they may fall out from the regular nutrition programmes. They were perceived as difficult to access and frequently excluded from these interventions. Some pastoralist groups may have higher consumption of ASF than other populations but may still not have the best balanced diets. One participant suggested that this barrier could be overcome by targeting interventions at the stop points of their transhumance. In addition, increasing numbers of pastoralists tend to leave the most vulnerable family members behind at base-camp, where fewer resources are available.

The recommendations given by participants were in line with the FAO 'key recommendations for improving nutrition through agriculture' and 'Guiding Principles on Agriculture Programming for Nutrition' (FAO 2013b; FAO 2015a). Livestock Emergency Guidelines (LEGS) provide guidance for humanitarian livestock projects but do not include comprehensive advice on human nutrition (FAO 2015b). Women face many challenges, some of which may be ameliorated through livestock, which are considered transformative agents in agriculture-based rural areas. Gender needs to be skilfully addressed; however, gender issues are not always included in agricultural development work (Colverson 2013). Better gender-disaggregated data collection and analysis could enable policy makers to improve women's productivity and family welfare (FAO 2011).

\subsubsection{Challenges}

Participants in the KIIs and RPW identified different types of challenges, which may affect the ability to ensure good practices in project design and implementation. These challenges were mostly related to cultural, operational, funding, or technical capacity aspects, while others were intrinsic to emergency crises, etc. and are compiled in Box 2. Some aspects such as the difficulty of incorporating explicit nutrition objectives and indicators at intervention design level, mostly due to the lack of capacity and problems arising from 'funding mismatch' were controversial. Best design and implementation practices are not always supported by timelines, resource allocations, project funding cycles, or structure. Therefore, donors are encouraged to facilitate this process of integration of agriculture and nutrition in their schemes. Some of these intrinsic difficulties could be addressed by seeking synergies to optimise resources and delivery platforms (e.g. nutrition education of pastoralist through livestock programmes). Another barrier in the Sahel region was at the political level, as livestock is essential for economic growth and is still not considered a tool towards attaining food and nutrition security. Beyond the rapid response needs of recurring emergencies in the Sahel, it is important to consider long-term interventions in food systems for development and resilience, such as creating effective cooperative schemes and markets, fixing value chain inefficiencies, ensuring fair prices, etc. to generate income for smallholders, and also to increase access to ASF for households without livestock. 
Box 2 Reported challenges of interventions

Cultural challenges, created by the social systems or the behaviour of the beneficiaries:

1) Aspects already discussed of child feeding and caring practices, taboos, hygiene, water use, etc.

2) Pastoralists think sometimes in terms of animal food security rather than household; however, they might not get much return from their animals (they do not sell or eat them). Even during droughts, it can be difficult to convince them to destock their herds. The perception of 'social status' needs to be changed.

Operational challenges, related to intervention implementation:

1) Large scale national interventions may lose efficacy when they are too centralised.

2) Programs tackling too many elements can be cumbersome and inefficient.

3) Surveillance tool limitations often rely on a weak capacity for good quality data collection and may not have added value for farmers, who 'give information to the mediators to receive it back later'.

4) Lack of long-term national strategies in countries where institutions mainly react to emergencies, obtain no positive impact on overall poverty.

5) Despite political will, limited resources often do not allow strategic approaches or effective monitoring and impact evaluation.

6) Sometimes aid does not reach the most vulnerable households due to pressure from community power groups which need to be kept content (e.g. social arrangements for the distribution of animal feed).

7) Restocking for herd reconstitution is logistically complicated and, in the mid-term, it might be easier for beneficiaries to give, after one or two cycles, the offspring to other households.

Funding challenges, related to the funding strategy:

1) Emergency funding cycles often involve very short periods (between just a few months and 3 years), which lead to failure to implement systematic impact assessment.

2) Often project calls have a pre-fixed idea and tight funding; thus, there is little flexibility to adapt to the initial findings or to add relevant components detected during preparation and implementation.

3) Livestock is not a high priority for funders, except for emergency responses. No long-term preventative approaches are considered.

4) Multi-sectoriality is not always promoted by donors, who still tend to work in silos. There is a need for better integration and consideration at higher level.

Income interference challenges, related to the income expenditure prioritisation:

1) As discussed, increases in milk production can lead to reduced milk consumption due to good sale prices and enhanced market access. As a result, families may buy powder milk instead or consume no milk at all.

2) Alternatively, reduction of maternal time and increased milk production can also interfere with breastfeeding practices, reducing the proportion of exclusive breastfeeding and replacing it with animal milk.

3) Upgrading business skills may lead to investments in the business at expense of the family needs.

Expertise challenges, related to the lack of knowledge:

1) Lack of knowledge and expertise on the biology and the production systems of livestock in the humanitarian institutions, which are mostly plant production oriented.

2) Livestock and nutrition professionals 'speak a different language', which makes it difficult to collaborate and find common grounds.

3) Interest in nutrition is growing among livestock organisations; however, there is still a lack of understanding and expertise, mainly regarding indicators and linkages.

4) Limited analytical capacity.

Emergency challenges, related to humanitarian crises:

1) At the time of crises, pastoralists may migrate, with the challenges highlighted. However, pastoralists migrating earlier tend to be better off and manage to keep more animals by the end of the crises.

2) Lack of effective early warning systems, which are particularly poorly developed for livestock.

3) Due to inefficient warning systems and to project administrative and logistic aspects, actions in emergencies often arrive very late, when animals are already dying.

5) Speculation with livestock is ruthless during emergencies.

6) In the Sahel rural areas, there is a lack of bank credit for restocking post-emergencies (at high prices).

7) Destocking is a controversial term for pastoralists, associated with times of hardship.

8) Complexity of the pastoral crises and lack of clear guidance for specific contexts.

9) The decision on the type of production system to prioritise may differ according to livelihoods or nutrition considerations, and there are important trade-offs.

\section{Other challenges}

1) Restocking interventions often do not consider aspects such as land degradation and do not conduct environmental impact studies, relevant to sustainability.

2) Seasonal scarcity of food and feed resources.

3) Animal transfer interventions can introduce foreign diseases to the communities and can affect severely the local livestock. This has happened even after vaccination and deparasitisation.

4) The national veterinary services may be weak in some regions, and do not reach many rural areas.

The responses given by participants and the literature alike point to widespread flaws in the design of interventions in terms of assessing impact on nutrition. A DFID commissioned report in 2012 mapped research on nutritional improvement through agricultural interventions, finding that among over 150 recent research projects, fewer than $15 \%$ were designed in a way that could contribute to understanding that relationship (Hawkes 
et al. 2012). These lacunae in design are recurrent issues that, until appropriately addressed, will hinder nutritionsensitive agriculture, especially livestock aspects. Evidence is poor and fragmented, and even when focused a single pathway, it often only addresses a small portion of such a pathway (Leroy and Frongillo 2007; Masset et al. 2012; Grace et al. 2018). Key informants, who were consulted, recommended interventions 'with theoretical potential to improve nutrition', but evidence from welldesigned projects is necessary before they can be confidently taken to scale.

\subsection{Monitoring and evaluation}

Participants highlighted the importance of assessing the extent to which existing livestock interventions/policies contributed to improved diets and reduced malnutrition and the sharing of this information. They considered the measurement and monitoring of nutritional outcomes a key challenge; $79 \%$ of the RPW participants acknowledged to having never or rarely monitored the nutrition impact of a livestock intervention (Fig. 2). Particularly noted was the mismatch among livestock production (indicators at farm level, such as increased production and number of animals to sell), food security indicators (at household level, such as food availability and accessibility) and nutrition indicators (intrinsically at individual level, such as dietary diversity or growth, particularly women and children) (Haesler et al. 2017). Suggested indicators are compiled in Table 2. The choice of these indicators should depend on the type of intervention and what is feasible. Many nonnutritional indicators can be turned into 'nutrition-sensitive' indicators (e.g. increase of production vs increase of micronutrient-rich production; household availability vs maternal and child intake, etc.).

For agricultural/livestock interventions, it is important to measure at least some intermediate outcomes such as consumption (ideally at individual level). Changes in dietary diversity scores were reported to have been used in household targeting and were considered a relevant indicator (Leroy and Frongillo 2007). Some project case studies presented looked at dietary diversity and consumed food groups, taking measurements at baseline and at endline, but results are not yet published (Bonde 2015). Attention to individual food groups were said to help understanding of changes in consumption patterns arising from the intervention as well as the impact pathways used by the interventions (e.g. preliminary data from Burkina Faso suggested that a chicken intervention increased dietary diversity through increased consumption of fish via the income pathway). Dietary diversity may be insensitive to increases in the consumption of a food group that was already being consumed (e.g. more milk consumed as a result of a dairy intervention), and so alternatives to measure specific intakes of commodities of interest (e.g. volume of children's milk intake, weight of meat consumed by women of reproductive-age, etc.) can be considered. Stunting was proposed as a good functional marker for multisectoral programmes, although due to its long-term and multicausal nature, it may be less sensitive and more difficult to interpret when key factors (e.g. health, water and sanitation) are not addressed. The FAO Compendium of indicators for nutrition-sensitive agriculture can be a

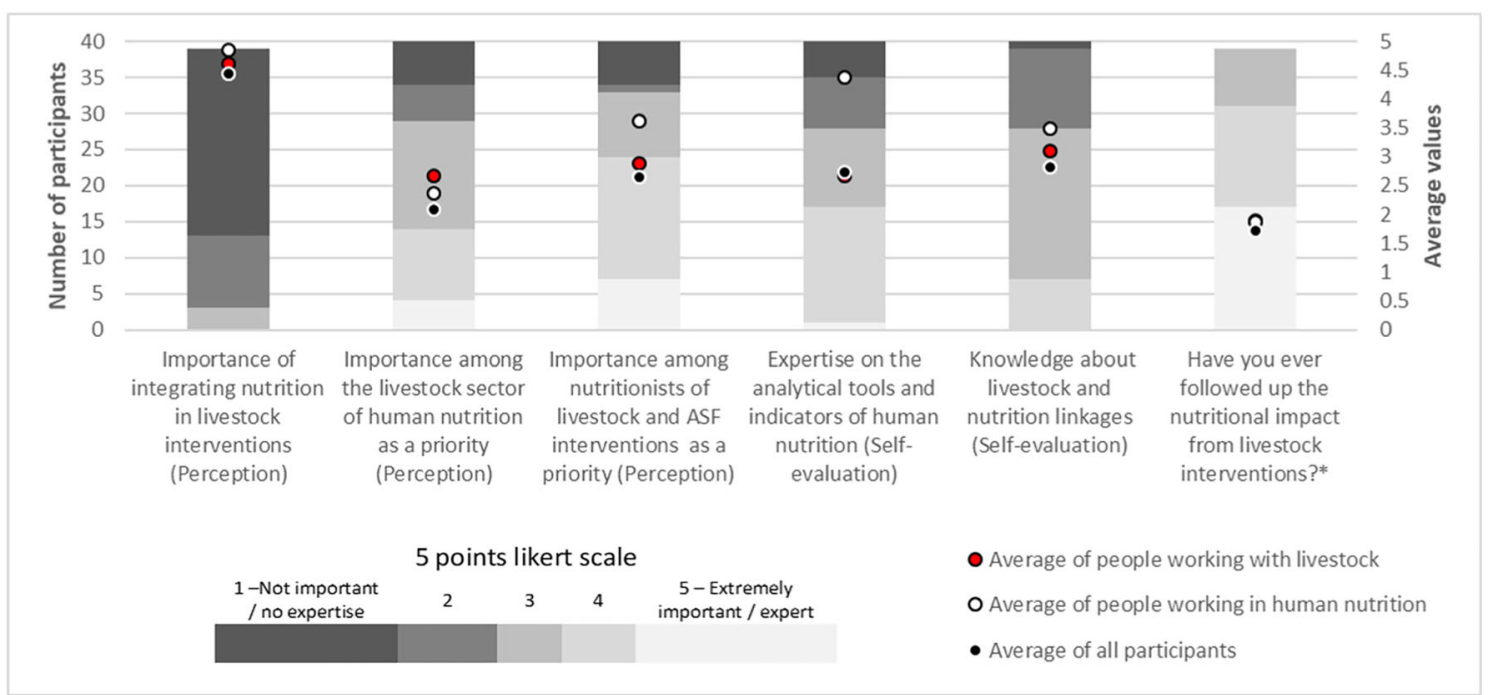

Fig. 2 Perceptions of workshop participants of the importance given to and their knowledge and experience of integrating livestock and human nutrition. *This question only had three options: $1=$ never (dark grey),
$2=$ sometimes and $3=$ frequently (clear grey). $n=40$; collected at the start of the workshop 
useful source of the choice of key indicators (FAO 2016).

Other concerns were related to the wide variety of existing indicators, the lack of institutional expertise and the complexity of their interpretation. Some indicators were said to have been designed and validated for nonlivestock agriculture activities and were not easy to adapt to livestock and ASF (e.g. food stocks, average dietary energy supply). At the same time, some participants thought that current indicators could be restrictive and that 'thinking outside the box' needed to be encouraged. Monitoring negative unintended side-effects ('do no harm' principle), and differentiating between process (to monitor the activities carried out) and impact indicators (to evaluate whether the activity had achieved the intended results) were also perceived as critical.

\subsection{Coordination}

There was agreement that progress in nutrition requires increased intersectoral coordination to address the multiplicity of causes. A healthy diet cannot be based on a single commodity, but rather needs a balanced food group intake, which requires connections among agriculture, livestock and nutrition, which at present are not sufficiently close. The KIIs and RPW participants highlighted the importance of different ministries, UN agencies and NGOs working collaboratively and in a coordinated manner. Coordination gaps were reported at two levels: among sectors (agriculture/livestock/nutrition) and among international actors, civil society, government institutions, and researchers. Some participants claimed that all interventions need to be centrally registered, to avoid overlapping and ensure that all projects are in line with national policies. Governmental coordination was perceived to be sometimes more political than technical, and the administrative procedures for project/programme design and implementation were described as slow and inefficient and, at times, complex and unclear. Collaboration among institutions (governmental and non-governmental) was reported to be not always possible due to tight internal structures ('in silos') and procedures. One participant explained that there are different schools of thought, even within institutions, leading to lack of internal coordination. Generally, technical meetings were described as sector-specific and did not include other technical expertise (e.g. nutritionists in livestock meetings or departments, and viceversa). The inclusion of different sectors in guidance documents was seen as necessary to promote collaboration.

Participants said they would welcome the creation of specific spaces at national level to share experiences on what was working well and seek operational synergies to optimise the efforts of institutions facing common problems. Actions to foster sector coordination and integration were proposed, for example among 'clusters', by creating thematic groups across clusters (the cluster approach, set by the Humanitarian Reform Agenda in 2005, aims at strengthening preparedness and technical capacity to respond to humanitarian emergencies in different sectors, e.g. food security, nutrition); or the creation of collaborative units between public health and agriculture departments in governments and organisations for the systematic integration of nutrition in agriculture. The lack of a common language and understanding was also emphasised. Certain actions such as: creation of a specific 'community of practice', incorporation of a specific and extensive human nutrition component in the LEGs guidance (as well as expanding the knowledge and use of this tool), building and strengthening capacity for intersectoral integration in governmental and nongovernmental institutions (including training in human nutrition in livestock sciences, universities and pastoral field schools), or creating networks and opportunities for collaboration, such as the Dakar RPW, which can be reproduced in other regions, could strengthen communication.

The main coordination challenges identified related to: leadership conflict or lack of leadership; an undermining attitude and lack of willingness to collaborate; resource and expert time constraints; lack of institutional, intersectoral consultation processes; lack of communication; targeting (geographical and at household level) and conflicting prioritisation; as well as a lack of common language and interests. Some opportunities, identified for progress, were the existence of international frameworks such as REACH ('Renewed Efforts Against Child Hunger and undernutrition' initiative) to facilitate and advocate for this, the growing awareness of funders for integrated projects or the existence of strong multidisciplinary platforms.

\subsection{Gaps in knowledge}

Livestock's role in nutrition was believed to have been less explored than crop agriculture. The KII identified gaps related to the lack of clear guidance and/or comprehensive research and evidence on what works. TANGO (Technical Assistance to NGOs) and IFPRI/A4NH prepared a report in 2015 on the uptake of science by NGOs (TANGO 2015) and highlighted the concerns among international NGOs about the lack of evidence for integrated agriculture and nutrition programming to implement tested approaches and the possible misdirection of human and financial resources. Since appropriate evaluation of the nutritional impact of livestock is rare (Masset et al. 2012), the evidence gaps identified are numerous. A major limitation of the interventions is that they were mainly not designed for nutrition impact assessment and they did not measure selected indicators at baseline, which challenged the ability to obtain adequate evaluation. Given the limited resources to respond to all the needs and funding cuts, partnerships among implementers and researchers would be advis- 
Table 2 Indicators identified by participants for use to assess nutritional impact of livestock interventions

\begin{tabular}{|c|c|c|c|c|c|c|}
\hline Food Availability & $\begin{array}{l}\text { Food Access } \\
\text { (Household) }\end{array}$ & $\begin{array}{l}\text { Food consumption } \\
\text { (Individual) }\end{array}$ & $\begin{array}{l}\text { Environmental } \\
\text { disease }\end{array}$ & Care Practices & Gender & Nutritional status \\
\hline $\begin{array}{l}\text { - ASF/food stocks } \\
\text { available (in a } \\
\text { given period) at } \\
\text { HH/market } \\
\text { - Per capita } \\
\text { ASF/food supply } \\
\text { (FBS) } \\
\text { - ASF/food ratio } \\
\text { self-sufficiency } \\
\text { (FBS) } \\
\text { - Stability of } \\
\text { ASF/food supply } \\
\text { - Availability of } \\
\text { milk throughout } \\
\text { the year } \\
\text { (seasonality) } \\
\text { - Total household } \\
\text { ASF/food } \\
\text { production (e.g. } \\
\text { litters milk/day) } \\
\text { - Number of } \\
\text { reproductive } \\
\text { animals } \\
\text { - Livestock } \\
\text { productivity } \\
\text { - Production } \\
\text { efficiency } \\
\text { - Production } \\
\text { diversity } \\
\text { - Quantity of ASF } \\
\text { production sold } \\
\text { - Number of HHs } \\
\text { uptaking } \\
\text { intervention/- } \\
\text { activity }\end{array}$ & 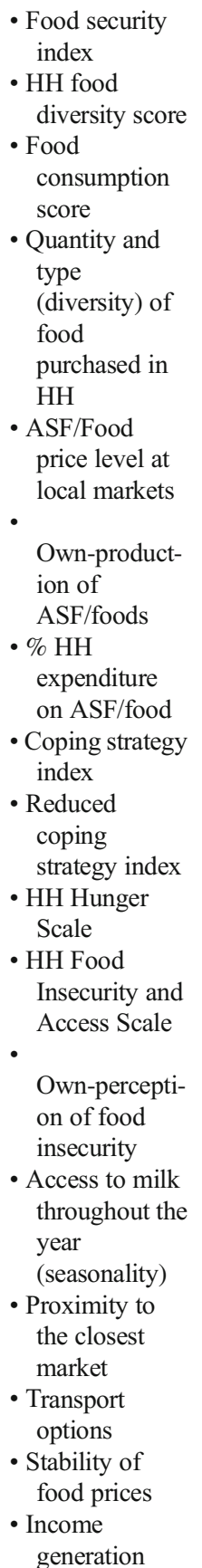 & $\begin{array}{l}\text { - Individual dietary } \\
\text { diversity scores } \\
\text { (Women dietary } \\
\text { diversity score, } \\
\text { Women and } \\
\text { Infant Minimum } \\
\text { dietary diversity } \\
(6-23 \text { m)) } \\
\text { - Nutrient intake } \\
\text { - Consumption of } \\
\text { iron-rich or } \\
\text { iron-fortified (or } \\
\text { vitamin A) } \\
\text { foods } \\
\text { - \% of } \\
\text { women/children } \\
\text { consuming } \\
\text { ASF/ } \\
\text { milk/eggs/dried } \\
\text { meat } \\
\text { - Number of meals } \\
\text { a day of } \\
\text { children/adults }\end{array}$ & $\begin{array}{l}\text { - Animal vaccination } \\
\text { rate } \\
\text { - Animal mortality } \\
\text { rate } \\
\text { - Prevalence of } \\
\text { animal disease and } \\
\text { zoonoses } \\
\text { - Morbidity rate in } \\
\text { human (diarrhoea, } \\
\text { respiratory } \\
\text { infection) } \\
\text { - Environmental } \\
\text { hygiene (e.g. \% of } \\
\text { HHs having } \\
\text { latrines, access to } \\
\text { drinking water or } \\
\text { hand washing } \\
\text { facility; faecal } \\
\text { coliforms in } \\
\text { drinking water } \\
\text { - Knowledge, } \\
\text { Attitudes and } \\
\text { Practices } \\
\text { indicators for food } \\
\text { hygiene (e.g. \% of } \\
\text { HHs washing } \\
\text { hands before } \\
\text { eating, or after } \\
\text { handling animals) } \\
\text { - Indicators of } \\
\text { hygiene in food } \\
\text { facilities (e.g. } \\
\text { slaughterhouses } \\
\text { and } \\
\text { transformation) } \\
\text {-\% of the production } \\
\text { meeting quality } \\
\text { standards }\end{array}$ & $\begin{array}{l}\text { - Infant and Young } \\
\text { Child Feeding } \\
\text { practices (children } \\
\text { ever breastfed, } \\
\text { early initiation of } \\
\text { BF, exclusive BF } \\
\text { under } 6 \text { m, } \\
\text { continued BF at } 1 \\
\text { and } 2 \text { y, } \\
\text { introduction of } \\
\text { solid, semi-solid or } \\
\text { soft foods, } \\
\text { minimum meal } \\
\text { frequency of } \\
\text { infants, minimum } \\
\text { acceptable diet for } \\
\text { infants, } \\
\text { age-appropriate } \\
\text { BF, predominant } \\
\text { breastfeeding } \\
\text { under } 6 \text { m, } \\
\text { duration of BF) } \\
\text { - Health seeking } \\
\text { behaviour } \\
\text { practices (e.g. } \\
\text { Ante/post-natal } \\
\text { care rate, } \\
\text { colostrum intake } \\
\text { rate, health } \\
\text { services access) } \\
\text { - School attendance } \\
\text { - Rate of impregnated } \\
\text { mosquito net usage }\end{array}$ & $\begin{array}{l}\text { - Female workload } \\
\text { (e.g. number of } \\
\text { hours spent in } \\
\text { livestock } \\
\text { activities per day, } \\
\text { ratio of hours } \\
\text { spent in livestock } \\
\text { activities by } \\
\text { male/female) } \\
\text { - \% of the revenue } \\
\text { controlled by the } \\
\text { women } \\
\text { - Women } \\
\text { Empowerment in } \\
\text { Agriculture Index } \\
\text { - \% of men } \\
\text { participating in } \\
\text { nutrition } \\
\text { education } \\
\text { - \% of women } \\
\text { participating in } \\
\text { intervention } \\
\text { committees and } \\
\text { activities }\end{array}$ & $\begin{array}{l}\text { - Acute } \\
\text { malnutrition } \\
\text { (prevalence of } \\
\text { severe and } \\
\text { moderate } \\
\text { wasting -low } \\
\text { weight for } \\
\text { height-, } \\
\text { nutritional } \\
\text { oedema, low } \\
\text { MUAC) } \\
\text { - Chronic } \\
\text { malnutrition } \\
\text { (prevalence of } \\
\text { severe and } \\
\text { moderate } \\
\text { stunting-low } \\
\text { height for age) } \\
\text { - Prevalence of } \\
\text { severe and } \\
\text { moderate } \\
\text { underweight } \\
\text { (low weight for } \\
\text { age) } \\
\text { - Mortality rate } \\
\text { - Overweight and } \\
\text { obesity } \\
\text { prevalence } \\
\text { - Body Mass index } \\
\text { (or MUAC for } \\
\text { pregnant } \\
\text { women) } \\
\text { Prevalence of } \\
\text { micronutrient } \\
\text { deficiencies: } \\
\text { anaemia } \\
\text { (haemoglobin), } \\
\text { level of iodine } \\
\text { in urine, retinol } \\
\text { in blood } \\
\text { (vitamin A), etc. }\end{array}$ \\
\hline
\end{tabular}

$\mathrm{BF}=$ breastfeeding; FBS=Food Balance Sheets, $\mathrm{HH}=$ household; $\mathrm{m}=$ months; MUAC = Middle Upper-Arm Circumference; $\mathrm{y}=$ years

able, in order to contribute to gathering good quality evidence whilst implementing development projects. Researchers should be involved from very early in the design process. New interventions require careful design and data collection. Funding schemes should allow and foster these types of partnerships and the inclusion of detailed impact evaluation, including impact pathways.

Specifically, in relation to ASF consumption, the need was reported for: i) greater clarity of their role in nutrition security and trade-offs (e.g. better understanding of their health 
properties, such as risks of overconsumption or the importance of fermented milks in non-communicable diseases); ii) establishing recommended intakes for the different population groups (e.g. clarity on desirable consumption of meat by age group); iii) increasing knowledge on how ASF transformation affects preservation of their nutrition value (including dissemination of the learning from current practices, such as the effect of using citric acid instead of vinegar for dried meat or packaging for meat preservation); and iv) better understanding of the socio-cultural and behavioural aspects of ASF consumption (e.g. drivers of choice, or the role of traditional culinary practices related to ASF (e.g. couscous with milk)). One specific area where research could provide efficient innovative technical solutions is storage, processing and preservation. More research is needed on simple and effective traditional techniques that allow delivery of safe ASF in a stable manner. The need for better understanding of marketing and trading parameters and the relationship between commercialisation and consumption of the produced ASF was also highlighted. Finally, the lack of information on the role of bee and insect rearing in nutrition and health was mentioned.

Regarding livestock interventions, more evidence was seen as necessary on the effectiveness of the projects, programmes and policies implemented, as well as which livestock interventions were more efficient in improving diets. This information could contribute to informed prioritisation of investment. Particularly, cost-effectiveness of livestock interventions to prevent malnutrition would be helpful for decision-making. The evidence and data related to investment in sustainable livestock is scattered and not always robust; in addition, the contributions to nutrition are not conventionally factored into estimates of net cost benefit of animal production. In countries with high malnutrition levels and high livestock investment, comparing data on investment in livestock (in the context of its different roles) with other efforts to treat and prevent malnutrition might be highly relevant and worth undertaking.

It is important to produce evidence but also to share it, and participants felt this is not always done, particularly when results were negative or absent. Even when results were positive, detailed information was not always available for consultation. Transparency and dissemination of lessons learnt are essential to moving forward in this field. Participants in this study were likely to be more familiar, interested and informed on the topic than the average professional, so the real situation in the sector in terms of awareness and interest in integration is probably worse. The results raise a relevant question on why the current evidence is not reaching practitioners, and whether there are bottlenecks in the cascade of information downstream or, conversely, an overload of information on agriculture, which may be difficult to disentangle by sector for professionals on the ground. Recent initiatives for data sharing in nutrition are likely to improve this. Broader dissemination of livestock situation analysis through data sharing would also be advisable. In addition, available evidence is not always well presented for practitioners and policy-makers, and peer-reviewed papers are sometimes difficult to obtain. More user-friendly summary formats, with links to expanded documents when necessary, might improve access and reach.

\section{Conclusions}

There was general agreement on the importance of livestock development and ASF to reduce the high levels of malnutrition in the Sahel, where they coexist with the presence of high levels of livestock, notably in pastoral areas. However, a landscape analysis mapping the US Government's global hunger and food security initiative 'Feed the future' activities showed that fewer than $10 \%$ had a livestock component (Du 2014). This paper presents qualitative data from field actors on the perceptions and current state of knowledge about livestock-nutrition linkages, which were mostly in line with current scientific thinking, but also draws attention to points that deserve action in order to build up further evidence. Our findings highlight an underlying lack of connection between livestock and the nutrition sectors, supported by the literature reviewed, where livestock projects rarely assess nutrition impact. Among the livestock sector stakeholders, the multifactorial nature of nutrition and the extent to which multi-sectorial strategies (including agriculture, water and sanitation, education, etc.) can contribute was not well-known. The specific nutrition value of ASF was also not fully realised within the sector promoting production, explaining the frequent lack of specific nutrition objectives. This research, based on the systematic documentation of a participatory process, also tried to understand challenges and constraints that might influence this lack of integration, and compile lessons learnt, to identify areas where action is needed to leverage nutrition in livestock interventions more widely. Some specific ideas, identified by field experts, may not be underpinned by evidence in the existing literature, yet they are important to be understood as sector perceptions and some of them may constitute relevant research gaps. Overall, the findings provide insightful 'food for thought' to inform new strategies and initiatives that, if promoted at government or donor level through funding procedures, could cascade down into both sectors and foster coordination, help overcome the challenges, and build up evidence. The findings could also be used for advocacy purposes, particularly since the solutions and ideas proposed do not arise from external agents, but from the sector itself, and contain good advice on practical aspects.

Although the underlying issues are likely to be common, replicating this experience in other regions could complement this picture and result in an overall picture of the sector. In 
addition, it would further sensitise practitioners to the global problem of lack of nutrition knowledge among other sectors and promote coordination among them and information sharing. Finally, awareness and understanding of impact pathways is essential so as to avoid or mitigate negative impacts and 'do no harm'.

Acknowledgements This work was funded by the Food and Agriculture Organization of the United Nations (FAO). We thank the participants of the different parts of this study for their support and contributions. We are also grateful to: David Patrick and Vincent Martin (FAO Regional Resilience, Emergency and Rehabilitation Office for West Africa/Sahel, REOWA) and their staff for the institutional and logistic support provided throughout the study. In particular, we thank Abdou Aziz Thioune for his support in the preparation of the workshop as part of the steering committee and facilitator; Angela Kimani (FAO Resilience Team for Eastern Africa) for her help in the workshop preparation; Thomas Uthayakumar, Elvira Ucello and Charlotte Dufour (FAO Nutrition and Food Systems Division) for their help in extracting all the relevant information for this manuscript, critically reviewing the manuscript and providing technical advice. To Kristie Smith (Royal Veterinary College) and Judy Kimani (ILRI), we are grateful for proof-reading the manuscript. This project was funded by the European Commission Humanitarian Aid \& Civil Protection (ECHO), the FAO Regional Resilience, Emergency and Rehabilitation Office for West Africa/Sahel, REOWA (Dakar) and FAO Nutrition and Food System Division through the staff provided. PDS and PA completed the interviews; PDS drafted the manuscript; all authors organised and facilitated the regional workshop and critically reviewed the paper.

\section{Compliance with ethical standards}

Conflict of interests The authors declare that they have no conflict of interest.

The views expressed in this publication are those of the author(s) and do not necessarily reflect the views or policies of FAO.

Open Access This article is licensed under the terms of the Creative Commons Attribution-NonCommercial-ShareAlike 3.0 IGO License, which permits any non-commercial use, sharing, adaptation, distribution and reproduction in any medium or format, as long as you give appropriate credit to the Food and Agriculture Organization of the United Nations (FAO), provide a link to the Creative Commons licence, and indicate if changes were made. If you remix, transform, or build upon this article or a part thereof, you must distribute your contributions under the same licence as the original.

The use of the Food and Agriculture Organization of the United Nations (FAO)'s name, and the use of the Food and Agriculture Organization of the United Nations (FAO)'s logo, shall be subject to a separate written licence agreement between the Food and Agriculture Organization of the United Nations (FAO) and the user and is not authorized as part of this CC-IGO licence. Note that the link provided above includes additional terms and conditions of the licence.

The images or other third party material in this article are included in the article's Creative Commons licence, unless indicated otherwise in a credit line to the material. If material is not included in the article's Creative Commons licence and your intended use is not permitted by statutory regulation or exceeds the permitted use, you will need to obtain permission directly from the copyright holder.

To view a copy of this licence, visit http://creativecommons.org/licenses/ by-nc-sa/3.0/igo/.

\section{References}

African Union (2017). Report of the $9^{\text {th }}$ Meeting of the African Task Force on Nutrition and Development (ATFFND) Accelerating nutrition governance towards harnessing the demographic dividend in Africa.

Bageant, E. R., \& Barrett, C. B. (2017). Are there gender differences in demand for index-based livestock insurance? The Journal of Development Studies, 53(6), 932-952.

Baker, D., Mtimet, N., Pica-Ciamarra, U., \& Nsiima, L. (2016). Consumer's preferences for animal-source foods and retail outlets: The case of Tanzania. African Journal of Agricultural and Resource Economics, African Association of Agricultural Economists, 11, 3.

Bhutta, Z. A., Das, J. K., Rizvi, A., Gaffey, M. F., Walker, N., Horton, S., Webb, P., Lartey, A., \& Black, R. E. The Lancet Nutrition Interventions Review Group and the Maternal and Child Nutrition Study Group(2013). Evidence-based interventions for improvement of maternal and child nutrition: What can be done and at what cost? Lancet, 382(9890), 452-477.

Black, R. E., Allen, L. H., Bhutta, Z. A., Caulfield, L. E., de Onis, M., Ezzati, M., Mathers, C., Rivera, J., \& for the Maternal and Child Undernutrition Study Group. (2008). Maternal and child undernutrition: Global and regional exposures and health consequences. Lancet, 371(9608), 243-260.

Black, R. E., Victora, C. G., Walker, S. P., Bhutta, Z. A., Christian, P., de Onis, M., Ezzati, M., Grantham-McGregor, S., Katz, J., Martorell, R., Uauy, R., \& and the Maternal and Child Nutrition Study Group. (2013). Maternal and child undernutrition and overweight in lowincome and middle-income countries. Lancet, 382(9890), 427-451.

Bonde, D. (2015). Impact of agronomy and livestock interventions on women's and child dietary diversity in Mali. Field Exchange, 51.

Bonfoh, B., G. Fokou, S. Traore, P. Ndour, K. Roesel and S. Alonso (2014). Rapid integrated assessment of nutrition and health risks associated with the small ruminants value chain in 2 districts of Senegal: Dakar and Tambacounda. Research Report. ILRI. Nairobi. International Livestock Research Institute.

Colverson, K. E. (2013). "Closing the gender gap in agriculture: A trainer's manual." Nairobi, International Livestock Research Institute.

Deka, R., Grace, D., Lapar, M. L., \& Fahrion, A. (2012). Comparative risk assessment of pork value chain in Nagaland, Northeast India. Asian Journal of Agriculture and Development, 9(3), 85.

$\mathrm{Du}, \mathrm{L}$. (2014). Leveraging agriculture for nutritional impact through the feed the Futur initiative: A landscape analysis of activities accross 19 focus countries, in USAID/Strenthening partnerships, results and Innovvations in nutrition globally. Spring. Arlington.

Dury, S., A. Alpha and C. r. Bichard, Editor. (2014). What risks do agricultural interventions entail for nutrition? Working papers MOISA. C. CIHEAM-IAMM, INRA, Montpellier SupAgro. Montpellier, Franece.

FAO (1992). Meat and meat products in human nutrition in developing countries. Rome, Food and Agriculture Organization of the United Nations.

FAO (2011). The state of food and agriculture (2010-11): Women in agriculture: Closing the gender gap for development. Rome, Food and Agriculture Organization of the United Nations.

FAO (2013a). Milk and dairy products in human nutrition. Rome, Food and Agriculture Organization of the United Nations.

FAO (2013b). Synthesis of guiding principles on agriculture programming for nutrition. Rome, Food and Agriculture Organization of the United Nations.

FAO (2015a). Key recommendations for improving nutrition through agriculture and food systems. Rome, Food and Agriculture Organization of the United Nations.

FAO (2015b). Livestock emergency guidelines and standards (LEGS). Rome, Food and Agriculture Organization of the United Nations. 
FAO (2016). Compendium of indicators for nutrition-sensitive agriculture. Rome, Food and Agriculture Organization of the United Nations.

FAO/WHO (2014). Second international conference on nutrition (ICN2) outcome document: Rome declaration on nutrition. Rome, Food and Agriculture Organization of the United Nations and the World Health Organisation.

Grace, D., P. Dominguez-Salas, S. Alonso, M. Lannerstad, E. Muunda, N. Ngwili, A. Omar, M. Khan and E. Otobo (2018). The influence of livestock-derived foods on nutrition during the first 1,000 days of life. Research Report. ILRI. Nairobi, International Livestrock Research Institute.

Grillenberger, M., Murphy, S. P., Neumann, C. G., Bwibo, N. O., Verhoef, H., \& Hautvast, J. G. (2007). The potential of increased meat intake to improve iron nutrition in rural Kenyan schoolchildren. International Journal for Vitamin and Nutrition Research, 77(3), 193-198.

Haddad, L. (2000). A conceptual framework for assessing agriculturenutrition linkages. Food and Nutrition Bulletin, 21(4), 367-373.

Haesler, B., K. Fornace, M. Eltolth, J. Rushton, D. Grace and K. Roesel (2014). Rapid assessment of nutrition and food safety risks in dairy value chains in Tanzania. Research report series, ILRI. Nairobi, International Livestock Research Institute.

Haesler, B., Dominguez-Salas, P., Fornace, K., Garza, M., Grace, D., \& Rushton, J. (2017). Where food safety meets nutrition outcomes in livestock and fish value chains, a conceptual approach. Food Security, 9(5), 1001-1017.

Hawkes, C., R. Turner and J. Waage (2012). Current and planned research on agriculture for improved nutrition: A mapping and a gap analysis a report for DFID. London, Leverhulme Centre for Integrative Research on Agriculture and Health.

Hetherington, J. B., Wiethoelter, A. K., Negin, J., \& Mor, S. M. (2017). Livestock ownership, animal source foods and child nutritional outcomes in seven rural village clusters in Sub-Saharan Africa. Agriculture and Food Security, 2017, 6, 9.

IFPRI (2016). Global Nutrition Report 2016. From promise to impact: Ending malnutrition by 2030. Washington, DC, International Food Policy Research Centre.

Jensen, N., \& Barrett, C. (2017). Agricultural index Insurance for Development. Perspectives and Policy, 39(2), 199-219.

Johnston, D., S. Stevano, H. Malapit, E. Hull and S. Kadiyala (2015). Agriculture, gendered time use, and nutritional outcomes. A systematic review. Discussion Paper. IFPRI. Washington, D.C, International Food Policy Research Institute (IFPRI) and CGIAR Research Program on Agriculture for Nutrition and Health. .

Leroy, J. L., \& Frongillo, E. A. (2007). Can interventions to promote animal production ameliorate undernutrition? Journal of Nutrition, 137(10), 2311-2316.

Maslow, A. H. (1943). A theory of human motivation. Psychological Review, 50(4), 370-396.

Masset, E., Haddad, L., Cornelius, A., \& Isaza-Castro, J. (2012). Effectiveness of agricultural interventions that aim to improve nutritional status of children: Systematic review. BMJ, 344, d8222.

McPeak, J., Chantarat, S., \& Mude, A. (2010). Explaining index-based livestock insurance to pastoralists. Agricultural Finance Review, $70(3), 333-352$.

Meyer-Rochow, V. B. (2009). Food taboos: Their origins and purposes. Journal of Ethnobiology and Ethnomedicine, 5, 18.

Miller, L. C., Joshi, N., Lohani, M., Rogers, B., Loraditch, M., Houser, R., Singh, P., \& Mahato, S. (2014). Community development and livestock promotion in rural Nepal: Effects on child growth and health. Food and Nutrititon Bulletin, 35(3), 312-326.
Njuki, J. M., Wyatt, A., Baltenweck, I., Yount, K., Null, C., Ramakrishnan, U., Girard, A. W., \& Sreenath, S. (2015). An exploratory study of dairying intensification, women's decision making, and time use and implications for child nutrition in Kenya. European Journal of Development Research.

OCHA. (2016). Sahel: Overview of humanitarian needs and requirements. New York: United Nations Office for the Coordination o Humanitarian Affairs.

Picchioni, F., Aurino, E., Aleksandrowicz, L., Bruce, M., Chesterman, S., Dominguez-Salas, P., Gersten, Z., Kalamatianou, S., Turner, C., \& Yates, J. (2017). Roads to interdisciplinarity-working on the nexus among food systems, nutrition and health. Food Security, 9(1), 181-189.

Randolph, T. F., Schelling, E., Grace, D., Nicholson, C. F., Leroy, J. L., Cole, D. C., Demment, M. W., Omore, A., Zinsstag, J., \& Ruel, M. (2007). Invited review: Role of livestock in human nutrition and health for poverty reduction in developing countries. Journal of Animal Science, 85(11), 2788-2800.

Ruel, M. T., Alderman, H., \& and the Maternal and Child Nutrition Study Group. (2013). Nutrition-sensitive interventions and programmes: How can they help to accelerate progress in improving maternal and child nutrition? Lancet, 382(9891), 536-551.

Sadler, K., C. Kerven, M. Calo, A. Catley and M. Manske (2009). Milk matters: A literature review of pastoralist nutrition and programming responses. Addis Ababa, Feinstein International Center, Tufts University and Save the Children.

Sandford, J. and S. Ashley (2008). Livestock livelihoods and institutions in the IGAD region, in IGAD livestock policy initiative. FAO. Rome, Food and Agriculture Organization of the United Nations.

Speedy, A. W. (2003). Global production and consumption of animal source foods. Journal of Nutrition, 133(11 Suppl 2), 4048S-4053S.

SUN (2011). Scaling up nutrition- a framework for action (reprint), Geneva. Scaling Up Nutrition.

Swanepoel, F., A. Stroebel and S. Moyo (2010). The role of livestock in developing communities: Enhancing multifunctionality, University of the Free State, The Technical Centre for Agricultural and Rural Cooperation, International Livestock Research Institute.

TANGO (2015). Use of research by international NGOs working on agriculture and nutrition: Current practices and opportunities for enhancing research uptake and impact. Washington, D.C, Tango International.

UN. (2015). General assembly resolution- transforming our world: The 2030 agenda for sustainable development. New York: United Nations.

UN (2016). United nations decade of action on nutrition (2016-2025)work program, United Nations.

UN (2018). The sustainable development goals report. New York, United Nations.

UNICEF (2016). The state of the World's children. New York, The United Nations International Children's Emergency Fund.

Webb, P. (2013). Impact Pathways from Agricultural Research to Improved Nutrition and Health: Literature Analysis and Research Priorities. Background paper prepared for the ICN2 second international conference on nutrition. FAO/WHO, Geneva. The food and agriculture Organization of the United Nations and the World Health Organization.

Wiafe-Amoako, F. (2016). Africa 2016-2017. Baltimore: Rowman \& Littlefield.

WorldBank. (2014). Business and livelihoods in African livestock: Investments to overcome information gaps. Washington, D.C., WordBank. 


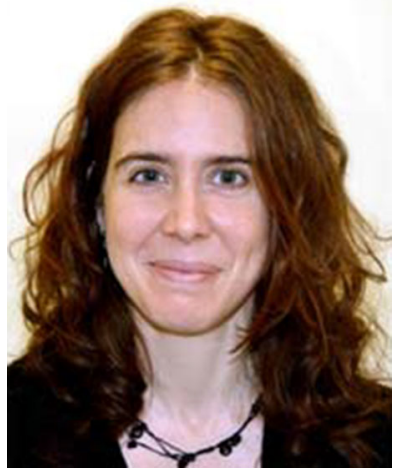

Paula Dominguez-Salas graduated in Veterinary Sciences (animal production specialty) in 1998 from the University of Zaragoza, Spain, where she also graduated in Food Sciences and Technology, and took a postgraduate degree in Agricultural Economics. She then obtained an $\mathrm{MSc}$ and $\mathrm{a} \mathrm{PhD}$ in International Public Health Nutrition at the London School of Hygiene and Tropical Medicine (LSHTM), where she works as Assistant Professor of Nutrition-sensitive agriculture, as a joint appointment with the International Livestock Institute (ILRI) in Nairobi, Kenya, being also part of the Leverhulme Centre for Integrative Research on Agriculture and Health (LCIRAH). Previously, she had worked as a Postdoctoral researcher in Nutrition at the Veterinary Epidemiology, Economics and Public Health Group at the Royal Veterinary College (RVC), London, UK. Her research focuses on the links between livestock food value chains, maternal and child nutrition, and gender in low-income settings of East Africa.

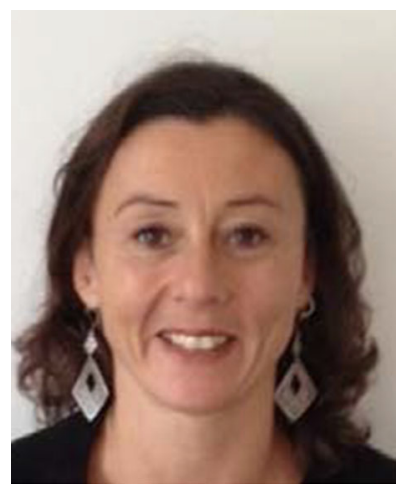

Domitille Kauffmann is a Nutrition, Food System and Resilience expert who graduated in Agronomy and Food Sciences (nutrition speciality) in 1999 from Montpellier SupAgro, France. She has worked for a wide range of aid agencies (donors, UN agencies, NGOs, Red Cross society) to support research, training and evaluations and to implement projects on Nutrition, Food Security, Livelihoods and Cash Transfer Programming in many different crisis contexts - including West, Central and East Africa; Middle and South-East Asia; Caribbean. Since 2013, she has been collaborating with FAO Nutrition and Food Systems division to support efforts in integrating nutrition in food and agriculture policies and programmes, including for emergency and resilience programming.

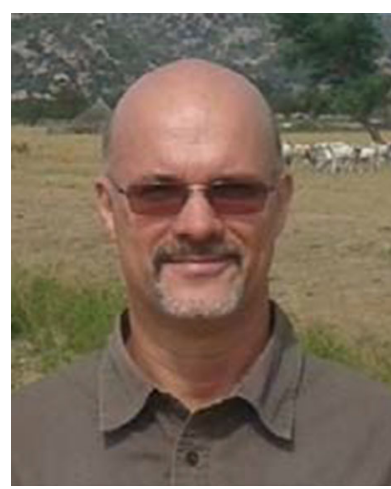

Christophe Breyne is a Food Security expert. Agronomist from Université Catholique de Louvain (UCL) in Belgium, he has worked on humanitarian, development and resilience aspects for $\mathrm{NGO}$, donors and UN to support implementation, monitoring and coordination on Food Security and Nutrition, Livelihood, Livestock and Cash Transfer projects in West Africa. Since 2014, he has worked as a regional (Sahel) Nutrition and Food Security consultant with FAO - REOWA (Regional Resilience, Emergency and Rehabilitation Office for West Africa/Sahel), Senegal, to support nutrition integration in food and agriculture policies and programmes

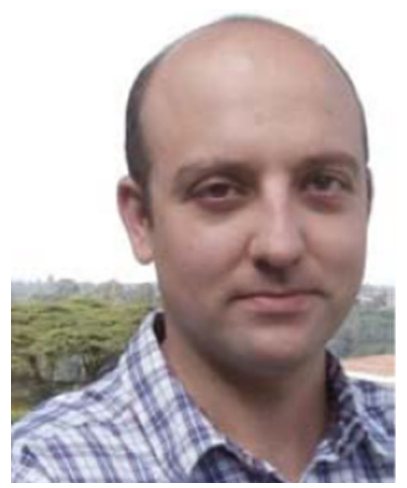

Pablo Alarcon is a lecturer in animal health economics at the Royal Veterinary College and also a member of the Leverhulme Center of Integrative Research in Agriculture and Health (LCIRAH) in London. Graduated in Veterinary Medicine at the University of Cordoba, Spain, he later obtained an MSc and a PhD in the areas of veterinary epidemiology and animal health economics at the RVC. His interest lies in understanding the economic drivers and factors associated with the emergence, prevention and control of animal diseases and public health risks across the different livestock food systems; in evaluating the economic burden of animal diseases for the different people in the food chain; and in the development of economic decision support tools for disease control. His past work has led him to investigate the impact and efficacy of control measures for diseases in pigs. As a post-doctoral research fellow he has investigated the structure, governance and food safety risks practices of the different livestock value chains operating in Nairobi, Kenya. 